\title{
The liquidators
}

\author{
A rose by any other name.
}

\section{Michael Garrett Farrelly}

He keeps telling me in a rolling Kazakh accent to call him Harry Lime, and at 90 miles an hour in the heart of a nuclear wasteland, I'm willing to oblige. I picked up Harry in one of the 'Stans. I can't remember which one, but I know the supreme leader just outlawed citrus for being a "Stalinist holdover". Every time I would ask someone in the 'Stans about the bizarre governments that seemed to bubble up in the region, I'd get a smile and a shrug. "Better than Russia," they'd say, and try to sell me a pirate DVD.

Harry Lime wasn't selling the latest Hollywood hits. He's a tour guide to the exclusion zone. I had to pay him nearly twice the cost of my round-trip businessclass ticket for the honour of having him drive me screaming into the Ukraine in his blood-red Chevy SUV. Harry knows all the border guards by name and his bribery with my money is generous to a fault. The last guards on the edge of the exclusion zone don't want a bribe. They just eye us both for a long time and nod us through. My guide with the Third Man obsession thinks this is a sign of good fortune.

We slap on three separate rad-readers apiece, all-inclusive to my tour package, thankfully. I like the redundancy more and more as we pass deeper into the zone. There's a lake filled with rusted-out tankers that Harry tells me has enough scrap metal to put Ukraine in the black for the next century. If only the metal wasn't soaked in enough radiation to contaminate all the ground water in Europe.

We hit the town of Pripyat and we're soaking in 500 microröntgens an hour according to all three of our readers. Harry claims he felt a bump and pulls to a stop to check the tyres and stretch. He warns me not to wander, that pockets of radiation strong enough to make me glow are hiding all around. I walk off towards a highrise apartment building and keep an eye on all my gauges, feeling like a deepsea diver back in the day of big metal helmets and hand-powered bellows.

I'd heard the stories about the silence. There was the tour group who all went mad and killed each other because they couldn't take the utter silence of the region, or the guy who ran screaming towards the reactor itself tearing at his clothes and crying out "Wormwood! Wormwood!" - and a dozen other scary tales. It's silent here, sure, but it's the stillness before something happens. A pregnant pause where you bring your own neuroses and listen to them bounce off the nothing.

Harry honks three times after checking all four tyres and five minutes later we're rolling out. Harry's willing to get me to the edge of the Red Wood forest but no further. He stops and parks about 1,000 yards from where I need to be and turns to me with a smile. I'm shivering so hard I think my heart will stop, and the heater is working just fine.

Harry reaches into the pocket of his battered army coat and pulls out a plastic hourglass, the kind you use for board games. He puts it on the dash and says:

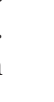

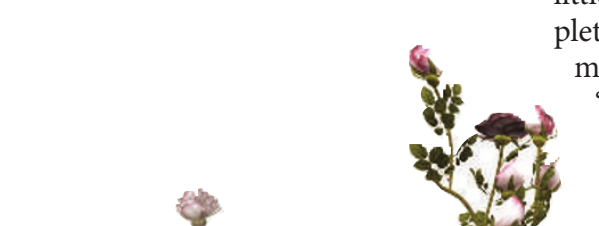

"Ten minutes." I know he means that's my time limit before he pulls off and leaves the crazy yank to rot.

Just outside I slip on the coveralls and seal up the helmet. With dead trees ahead and a taste like iodine in my mouth, I start my run.

The liquidators made this same trip back in 1986. Made it over and over with tonnes of nearly melting slag and bits of reactor shielding. The liquidators got a medal, some extra rations and a miserable death from any number of cancers brought on by exposure. Some of them were up on the roof over the reactor, picking up pieces of core with their bare hands.

It came out here, to Red Wood forest. I'm 200 metres out, according to the GPS. Some suit in Washington once told me over drinks that the CIA should post snipers around the Red Wood forest to protect against terrorists stealing radioactive soil. I'm 15 metres out when I think of the first time someone told me about Chernobyl. A little girl's vision of a smoking crater, complete with Wile E. Coyote standing in the middle with a hand-painted sign reading "Oops".

I kneel on something hard and pray it's not sharp enough to puncture the suit. I slip the vial and minitrowel out of my external pocket and open it. Borlaug Rose Species 0925, a handful of heavy, dark green pellets. I dig quickly with the trowel, one foot down, and drop the seeds. I'll confess to patting the filled-in hole and saying a little prayer. I'm up and running and Harry's honking the horn as a nervous tic.

Come next spring I'll get Harry, or someone just like him, to bring me back here. There will be a tangle of rosebushes where I was kneeling and the radiation level will be down, at least in the soil. Pretty pink roses, spliced to gobble up radiation, growing in the deadliest place on Earth. Oil slicks turning in floating gardens, chemical spills turned into orchards, that's the goal. Maybe it can all start here where too much ended.

Michael Garrett Farrelly is a librarian and writer in Chicago. He can be ound online at www. garrettfarrelly.net. 